\title{
A EFICIÊNCIA DA ESTIMULAÇÃO PRECOCE EM CRIANÇAS COM MICROCEFALIA CAUSADA PELO ZIKA VIRUS
}

\section{THE EFFICIENCY OF EARLY STIMULATION IN CHILDREN WITH MICROCEFALIA CAUSED BY ZIKA VIRUS}

\begin{abstract}
Jussymara Nepomuceno Teles Acadêmica do $9^{\circ}$ período de Fisioterapia da Universidade Presidente Antonio Calos UNIPAC. E-mail: jussymarateles@ gmail.com
\end{abstract}

Rejane Goecking Batista Pereira Professora orientadora. Especialista em Fisioterapia Neurológica pela UFMG, Especialista em Terapia Intensiva Neonatal pela Escola de Saúde Pública - MG, Fisioterapeuta Responsável Técnica Unimed Três Vales - e-mail: rejanegoecking@hotmail.com

Nileni Luiz De Deus

Acadêmica do $9^{\circ}$ período de Fisioterapia da Universidade Presidente Antonio Calos UNIPAC. E-mail: nilenideus@gmail.com

\section{Resumo}

No ano de 2015 o Brasil passou por um surto de infecção causada pelo vírus Zika. Em 2016 foi observado e confirmado pelas autoridades sanitárias do país que nas gestantes a incidência do Zika está diretamente ligada a implicação de bebês nascidos com microcefalia. A estimulação precoce de crianças com microcefalia deve acontecer de forma funcional para que a criança tenha motivação. Além da intervenção precoce, o tipo de intervenção e o grau de evolução do Sistema Nervoso Central podem interferir no resultado motor da criança. O profissional fisioterapeuta deve ser criativo e flexível para assim poder introduzir atividades que despertem o interesse da criança, mas também deve ser capaz de atingir o objetivo de melhorar a qualidade de vida da criança 
microencefálica. Este estudo trata-se de uma pesquisa qualitativa realizada através de revisão bibliográfica de maneira descritiva e exploratória, com o objetivo de demonstrar a eficácia da estimulação precoce de recém nascidos com a malformação do cérebro causada pelo vírus zika.

Palavras-chave: Microcefalia. Zika. Estimulação Precoce.

\begin{abstract}
In the year 2015, Brazil went through an outbreak of infection caused by the Zika virus. In 2016 it was observed and confirmed by the sanitary authorities of the country that in pregnant women the incidence of Zika is directly linked to the implication of babies born with microcephaly. The early stimulation of children with microcephaly must happen in a functional way so that the child has motivation. In addition to early intervention, the type of intervention and the degree of evolution of the Central Nervous System may interfere with the child's motor outcome. The professional physiotherapist must be creative and flexible in order to introduce activities that are of interest to the child, but must also be able to achieve the goal of improving the quality of life of the micro-encephalic child. This study is a qualitative research carried out through bibliographical review in a descriptive and exploratory way, aiming to demonstrate the efficacy of early stimulation of newborns with brain malformation caused by the zika virus.
\end{abstract}

Keywords: Microcephaly. Zika. Early Stimulation.

\title{
1 Introdução
}

Segundo o Ministério da Saúde a definição de Microcefalia é: "uma malformação congênita em que o cérebro não se desenvolve de maneira adequada". Essa malformação pode ser efeito de diferentes fatores e origens, como 
substâncias químicas e infecciosas, além de bactérias, vírus e radiação. Neste artigo será abordada a microcefalia causada pelo Zika vírus.

O primeiro caso de vírus Zika (ZIKV) foi identificado em humanos em 1952, de acordo com Dick, Kitchen, Haddow (apud SALGE et al., 2016) e descrito até o ano de 2007 como causador de infecções esporádicas mais concentrados na África e na Ásia.

A microcefalia teve um inesperado aumento de sua incidência no Brasil a partir do ano de 2015, inicialmente nos estados do Nordeste do país. O fato acarretou uma mobilização social e científica que levou o Ministério da Saúde a decretar emergência de saúde pública nacional, sendo tal decreto seguido pela declaração de emergência de saúde pública de interesse internacional da Organização Mundial da Saúde (OMS).

Após estudos que buscaram as causas do aumento da microcefalia, a hipótese formulada foi que a infecção congênita era causada pelo vírus Zika, com base nos relatos e as características epidemiológicas dos casos clínicos. Evidências foram acumuladas e no âmbito do raciocínio epidemiológico preencheram critérios que deram sustentação à hipótese.

A partir da grande mobilização científica levantada pelo assunto a Associação Brasileira de Fisioterapia Neurofuncional (ABRAFIN) emitiu um parecer sobre a estimulação precoce e a microcefalia, sendo assim este estudo trata-se de uma pesquisa qualitativa realizada através de revisão bibliográfica, motivada em compreender e interpretar as opiniões e expectativas que possam verificar a eficácia da estimulação precoce de recém nascidos com a malformação do cérebro, a pesquisa será realizada também de maneira descritiva e exploratória. Os critérios de inclusão das referências no estudo foram: artigos científicos disponíveis na íntegra e publicados em revistas, disponíveis em língua portuguesa e inglesa publicados no período de 2015 a 2019.

\section{Microcefalia causada pelo vírus Zika}


O Zika Vírus é um flavírus (família Flaviviridae) transmitido por meio da picada do mosquito Aedes aegypti, o qual foi, nos primórdios, isolado de uma fêmea de macaco Rhesus febril na floresta Zika, em Uganda, trata-se de uma doença febril aguda que causa manchas avermelhadas na pele, mas que, na maioria dos casos, evolui para cura (SÁ, CARDOSO, JUCÁ, 2016).

Anterior a epidemia do Zika vírus ocorrido no Brasil o conhecimento sobre essa doença era limitado, as informações conhecidas era de que esporadicamente aconteceram surtos do vírus em duas regiões da Oceania, a Micronésia e na Polinésia Francesa, esta última onde teria ocorrido o maior número de casos até então, sendo 17 episódios entre março de 2014 e maio de 2015 diagnosticado a malformações do sistema nervoso central, incluindo microcefalia, em fetos e recém-nascidos.

O aumento da incidência da microcefalia no país, foi percebida inicialmente no estado de Pernambuco, Albunquerque et al., (2018) diz em seu estudo que a investigação inicial dos casos de microcefalia em maternidade de referência no estado mostrou que $70 \%$ das gestantes apresentavam relato de quadro infeccioso associado ao quadro clínico de Zika.

Segundo Melo et al., (2016, p. 6) o ZIKV foi encontrado em líquido amniótico de gestantes, "com fetos com microcefalia detectada intraútero e em tecido de cérebros e placentas de neonatos e fetos mortos".

Os primeiros 42 casos de microcefalia investigados no Estado de Pernambuco apresentavam IgM antiZIKV no soro em 90,5\% dos casos e de $100 \%$ no LCR, confirmando a infecção congênita e neurológica pelo vírus Zika nos neonatos, uma vez que $\operatorname{IgM}$ materna não ultrapassa a barreira placentária ou hematoencefálica 7,53. A fim de confirmar a hipótese de relação entre o vírus Zika e a microcefalia, Martines (2016) levantou em uma investigação na Polinésia Francesa um excesso de casos de 
malformações neurológicas graves incluindo casos de microcefalia após o surto de ZIKV ocorrido em 2013 e 2014.

O Zika vírus pode ser identificado através de exame laboratorial com a detecção de RNA viral a partir de espécimes clínicos. O Instituto Evandro Chagas (IEC) foi o responsável pelo teste sorológico e a relação da sequência genética completa do Zika vírus. Por ser um vírus de curta duração orienta-se que o exame seja feito até o $5^{\circ}$ dia da manifestação dos sintomas (RODRIGUES, 2016).

Segundo a Organização Mundial da Saúde

[...] a microcefalia é caracterizada pela medida do crânio realizada, pelo menos, 24 horas após o nascimento e dentro da primeira semana de vida (até 6 dias e 23 horas), por meio de técnica e equipamentos padronizados, em que o Perímetro Cefálico (PC) apresente medida menor que menos dois (-2) desvios-padrões abaixo da média específica para o sexo e idade gestacional.

Segundo Viane, Figueiredo (2017), a microcefalia é uma condição que o recém-nascido $(\mathrm{RN})$ apresenta perímetro cefálico substancialmente menor, quando comparado ao de outras crianças do mesmo sexo e idade. Após a declaração da Emergência de Saúde Pública de Importância Nacional (Espin), declarada em 11 de novembro de 2015, o Ministério da Saúde adotou, devido a recomendações da OMS, em agosto de 2016, uma nova tabela de referência sendo que uma criança nascida de 37 semanas de gestação, a medida de referência do perímetro cefálico será 30,24 cm para meninas e $30,54 \mathrm{~cm}$ para meninos, sendo preciso consultar a tabela para cada idade e sexo. 
Algumas medidas podem ser tomadas para amenizar os problemas das crianças microencefálicas, dentre elas está à intervenção cirúrgica a fim de afastar ligeiramente os ossos cranianos, no período dos dois primeiros meses de vida, com o objetivo de impedir seu crescimento evitando assim a compressão do cérebro (RODRIGUES, 2018).

A microcefalia pode ser acompanhada de epilepsia, paralisia cerebral, retardo no desenvolvimento cognitivo, motor e fala, além de problemas de visão e audição. Cerca de $90 \%$ das microcefalias estão associadas com retardo mental, exceto nas de origem familiar, que podem ter o desenvolvimento cognitivo normal. $\mathrm{O}$ tipo e o nível de gravidade da sequela vão variar caso a caso (BRASIL, 2019).

O que é confirmado por Rodrigues (2018) em seu estudo, onde diz que até o primeiro ano de vida da criança com microcefalia devem ser identificados os cuidados que elas precisarão ter por toda a vida, dentre as consequências mais graves que acomete as pessoas com microcefalia destaca-se: o atraso mental, déficit intelectual, paralisia, convulsões, epilepsia, autismo, espasticidade, sendo assim o portador de microcefalia precisará de um acompanhamento de uma equipe multiprofissional durante toda a vida.

\section{A eficiência da estimulação precoce em crianças com microcefalia causada pelo Zika vírus}

Segundo Gianini (2018), desde 2015, o ano do surto do ZIKV, 16.900 mil casos de microcefalia foram registrados no país e apenas 35\% (5.915 casos) dos bebês são assistidos e passam pelo procedimento da estimulação precoce.

A maior parte dos casos de microcefalia causada pelo zika foram registrados na região Nordeste, sendo 58,6\% (9.903 casos), seguidos da região Sudeste 25\% (4.225 casos) e da região Centro-Oeste 7,5\% (1.267 casos) e 8,9\% (1.505 casos) divididos 
entre as outras regiões. Os cinco estados mais atingidos pelas notificações são Pernambuco com 16,4\% (2.771 casos), Bahia 15,7\% (2.653 casos), São Paulo 9,7\% (1.639 casos), Rio de Janeiro 7\% (1.183 casos) e a Paraíba com 6,9\% (1.166 casos), segundo Matta (2018).

Ainda de acordo com o autor supracitado a incidência da microcefalia causada pelo zika diminuiu em termos numéricos e, atualmente, foram registrados poucos casos. Isso fez com que praticamente não se fale mais do assunto na imprensa e na agenda política, "mas, em termos simbólicos, a epidemia do zika não acabou, porque suas repercussões continuam, e muitas questões científicas não foram respondidas".

O desenvolvimento motor é um acontecimento normal na vida do ser humano. É acompanhado de processos de crescimento, maturação e aquisição da competência, ganho de habilidades e reorganização psicológica. Crianças com microcefalia apresentam, normalmente, deficiências motoras e cognitivas, características que no futuro podem comprometer, significativamente, a qualidade de vida (BRASIL, 2016) (MONTENEGRO, 2016).

Devido ao distúrbio de desenvolvimento ocasionado pela malformação do sistema nervoso central, a criança com microcefalia apresenta como consequência, distúrbio sensório-perceptivo-motor. Em geral, as lesões não progressivas que ocorreram no sistema nervoso central (SNC) fetal ou infantil em desenvolvimento resultam em um grupo de desordens permanentes, entre outras, aquelas relativas ao desenvolvimento e à postura caracterizado por alterações sensoriomotoras, que por sua vez afetam a aquisição das habilidades motoras típicas e dos marcos do desenvolvimento como a capacidade de manipulação e deambulação e das reações de proteção, equilíbrio e retificação. Os distúrbios motores são frequentemente acompanhados de distúrbios da sensação, percepção, cognição, comunicação e comportamento e por epilepsia. Além disto, secundariamente, podem levar a distúrbios musculoesqueléticos como contraturas e deformidades (BRASIL, 2016). 
Assim, para oferecer um tratamento mais amplo, alguns métodos utilizados pela Fisioterapia e pela Terapia Ocupacional podem ser considerados diferenciais (COFFITO 2016).

Em geral, as lesões não progressivas que ocorreram no sistema nervoso central (SNC) fetal ou infantil em desenvolvimento resultam em um grupo de desordens permanentes, entre outras, aquelas relativas ao desenvolvimento e à postura caracterizado por alterações sensoriomotoras, que por sua vez afetam a aquisição das habilidades motoras típicas e dos marcos do desenvolvimento como a capacidade de manipulação e deambulação e das reações de proteção, equilíbrio e retificação (BRASIL, 2016).

Após o diagnóstico e com a criança clinicamente estável, o processo de intervenção deve ser iniciado, para, dessa forma, tratar as deficiências primárias, minimizar as secundárias e prevenir deformidades (COFFITO, 2016).

A estimulação precoce pode ser definida como um programa de acompanhamento e intervenção clínico-terapêutica multiprofissional com bebês de alto risco e com crianças pequenas acometidas por patologias orgânicas - entre as quais, a microcefalia -, tendo o objetivo de evitar ou minimizar os distúrbios do desenvolvimento neuropsicomotor, bem como de efeitos na aquisição da linguagem, na socialização e na estruturação subjetiva, podendo contribuir, inclusive, na estruturação do vínculo mãe/bebê e na compreensão e no acolhimento familiar dessas crianças (BRASIL, 2016).

Segundo a Associação Brasileira de Fisioterapia Neurofuncional

O conhecimento das anomalias cerebrais é de extrema importância para a detecção mais precoce possível dos transtornos do desenvolvimento neuropsicomotor (DNPM) em lactentes com microcefalia. E, devem ser acompanhados e monitorados através de programas de intervenção e estimulação 
precoce. A estimulação precoce de bebês nascidos com microcefalia promove a harmonia do desenvolvimento entre vários sistemas orgânicos funcionais (áreas: motora, sensorial, perceptiva, proprioceptiva, linguística, cognitiva, emocional e social) dependentes ou não da maturação do Sistema Nervoso Central. As principais alterações clínicas e funcionais encontradas são: displasia do quadril, rigidez acentuada apendicular e tônus axial diminuído, displasia do quadril em alguns casos, escavação de mácula, dificultando a visão central e posteriormente aquisição das funções visuais e das coordenações sensório motoras primárias, secundárias e terciárias. Déficit sensorial importante, irritabilidade, dificuldade em coordenar sucção deglutição e respiração e posteriormente atrasos nas funções motoras orais (BRASIL, 2016).

A fisioterapia em pediatria consiste em avaliar, planejar e desenvolver um programa de intervenção individualizado. A avaliação envolve os seguintes aspectos: limitações ou alterações, habilidades/ funcionalidade, motivação e queixas, o que permite a elaboração do programa de intervenção considerando as necessidades da criança e da família (SILVA, VALENCIANO, FUJISAWA, 2017).

Reavaliações, orientações e educação também são à base do programa terapêutico destacam a importância da abordagem pediátrica humanizada na fisioterapia, em que o profissional considere o paciente como ser distinto e pessoal; além de levar em consideração o aspecto lúdico, por exemplo, ao utilizar de ambientes alegres, recursos musicais e visuais atraentes, permitir a habituação ao local de terapia; e a afetividade ao ser carinhoso, pegar no colo, conversar, acalmar e sorrir (SILVA, VALENCIANO, FUJISAWA, 2017). 
Rodrigues et al., (2017) dizem quem os programas de estimulação precoce podem ser benéficos para qualquer recém-nascido de risco que apresente condições ou agravos de saúde que interfiram no seu desenvolvimento neuropsicomotor. "Para lactentes e crianças com microcefalia, a estimulação precoce deve ser iniciada logo após a constatação da mesma, buscando otimizar o desenvolvimento e prevenir ou minimizar sequelas e deformidades".

Segundo o parecer da ABRAFIN a estimulação auditiva pode ocorrer de forma isolada a fim de trabalhar gradativamente as habilidades auditivas de: atenção, localização, lateralização, discriminação, compreensão auditiva. Logo este aspecto pode ser eliciado conjuntamente com a estimulação de linguagem durante o momento lúdico e contextual. A estimulação visual, não tem que ser nada muito complexo, sendo necessário ocorrer desde os primeiros dias de vida, nas atividades de vida diária e nos contatos afetivos com o cuidador. Para realizar a estimulação é necessário criar experiências agradáveis através do brincar, para chamar a atenção da criança (BRASIL, 2016).

Portanto, os fisioterapeutas, para que possam ter sua atuação de maneira eficaz nesta população, devem ser capazes de reconhecer os processos do desenvolvimento neuropsicomotor da criança compreendendo-os a luz de modelos teóricos que possam embasar sua prática, apoiados em uma formação apropriada para escolher as melhores estratégias de avaliação e tratamento para minimizar estas deficiências e favorecer uma maior independência e qualidade de vida para essas crianças.

Sendo assim, a atuação da fisioterapia neurofuncional em pediatria é fundamental para possibilitar à criança a aquisição de habilidades motoras e interação com o ambiente, além de prevenir deformidades e contraturas que podem piorar seu quadro motor e também comprometer outros sistemas, como o respiratório. Existem inúmeras evidências na literatura que confirmam que a intervenção precoce, a prática, a repetição, a motivação, a experiência e o ambiente enriquecido favorecem o processo de 
neuroplasticidade, ou seja, às mudanças estruturais no sistema nervoso na organização e na quantidade de conexões entre os neurônios (BRASIL, 2016).

Segundo Xavier (2019) é importante frisar que as orientações devem ser individualizadas levando em consideração cada criança, devem também ser fornecidas pelo profissional especializado que está atendendo esta criança, a partir das necessidades da mesma.

\section{Considerações finais}

A partir de todo o exposto conclui-se que a literatura sobre essa temática ainda é principiante, porém a relevância desses casos contribuíram para a realização de estudos sobre a microcefalia, todos os estudos analisados mostram a importância de inserir as crianças em um programa de estimulação precoce, porém não descrevem como realizar essa estimulação na prática. Os achados clínicos foram descritos de forma semelhante nos estudos, com isso, foi observada a necessidade ser realizada uma boa avaliação para que o programa de estimulação precoce seja mais eficaz e atenda toda a população, além disso é necessário que sejam levantados dados precisos que quantifiquem a eficácia da estimulação precoce, sendo esse um tema possível para futuras pesquisas.

Contudo conclui-se que o trabalho do fisioterapeuta vai depender do quadro de evolução da criança: quantas sessões por semana, a intensidade e o tipo de estímulo a ser aplicado. Mas é sempre importante ressaltar que o trabalho deve ser multidisciplinar, ou seja, em conjunto com o trabalho de outros profissionais. Não existe um tratamento definitivo para a doença, todo o trabalho realizado pela fisioterapia e outros profissionais tem por objetivo a redução dos impactos que a criança sofre como decorrência do acometimento pela microcefalia, além disso, fica evidente nas pesquisas 
que a participação da família é indispensável, pois contribui de forma direta para a melhora da qualidade de vida das crianças microencefálicas.

\section{Referências}

ALBUQUERQUE, Maria de Fatima Pessoa Militão et al. Epidemia de microcefalia e vírus Zika: a construção do conhecimento em epidemiologia. Caderno de Saúde Pública 2018, p.34.

BRASIL. Associação Brasileira de Fisioterapia Neurofuncional. 2016. Disponível em: <http://abrafin.org.br/wp-content/uploads/2015/02/PARECER-MICROCEFALIA.pdf>. Acesso em: 22/05/2019.

BRASIL. Ministério da Saúde. Microcefalia: causas, sintomas, tratamento e prevenção. 2019. Disponível em: <http://portalms.saude.gov.br/saude-de-a-z/microcefalia>. Acesso em: 21/05/2019.

COFFITO. Sistema COFFITO/CREFITOs. Diagnóstico: Microcefalia. E agora?. 2016, 12 p. Disponível em:

<http://www.coffito.org.br/site/files/noticias/2016/CartilhaMicrocefalia_Final.pdf>. Acesso em: 20/05/2019.

DICK GW, KITCHEN SF, HADDOW AJ. Zika virus. I. Isolations and serological specificity. Trans R Soc Trop Med Hyg v. 46, nº 5, p509-20.

MATTA, Gustavo. Entrevista: Pesquisador da ENSP adverte que epidemia de zika não acabou. 2018. Disponível em: <http://www.ensp.fiocruz.br/portalensp/informe/site/materia/detalhe/44165>. Acesso em: 28/05/2019.

MARTINES RB, BHATNAGAR J, KEATING MK, SILVAFLANNERY L, Muehlenbachs A, Gary J, et al. Notes from the field: evidence of Zika virus infection in brain and placental tissues from two congenitally infected newborns and two fetal losses: Brazil, MMWR Morb Mor - tal Wkly Rep 2016; 65:159-60.

MELO, AS; MALINGER G, XIMENES R, SZEJNFELD PO, ALVES S, BISPO AM. Zika virus intrauterine infection causes fetal brain abnormality and microceph - aly: tip of the iceberg? Ultrasound Obstet Gy - necol 2016; 47:6-7. 
MONTENEGRO, Helder. Fisioterapia contribui para tratamento da microcefalia. 2016. Disponível em: < https://www.minhavida.com.br/saude/materias/20674-fisioterapiacontribui-para-tratamento-da-microcefalia>. Acesso em: 22/05/2019.

PANTELIADIS CP, HAGEL C, KARCH D, HEINEMANN K. 2015. Cerebral Palsy: A Lifelong Challenge Asks for Early Intervention. Open Neuro; Jun 26;9:45-52

RODRIGUES, Diana Coelho Regadas; DANTAS, Meryeli Santos de Araòjo; CUNHA, Ianka Maria Bezerra; REGIS, Thamyris de Sales. Estimulação precoce de crianças com microcefalia por zika vírus: revisão integrativa. Cadernos de Educação, Saúde e Fisioterapia, v. 4, nº 8, 2017.

RODRIGUES, Frank Aguiar. Anjos Marcados: um estudo da microcefalia no campo da medicina e das ciências jurídicas no Brasil. Científic@ - Multidisciplinary Journal v. 5, $\mathrm{n}^{\circ} .2,2018$.

SÁ, Fabiane Elpídio; CARDOSO, Kátia Virgínia Viana; JUCÁ, Renata Viana Brígido de Moura. Microcefalia e Vírus Zika: do padrão epidemiológico à intervenção precoce. Revista Fisioterapia e Saúde Funcional, v.5, nº 1, 2016.

SALGEL, Ana Karina Marques; CASTRAL, Thaíla Corrêa; SOUZA, Marília Cordeiro; SOUZA, Romilda Rayane Godoi Souza; MINAMISAVA, Ruth; SOUZA, Sandra Maria Brunini. Infecção pelo vírus Zika na gestação e microcefalia em recém-nascidos: revisão integrativa de literatura. 2016. Disponível em: <http://docs.bvsalud.org/biblioref/2017/03/832645/39888-172522-3-pb.pdf>. Acesso em: 22/05/2019.

SILVA, Allan dos Santos; VALENCIANO, Paola Janeiro; FUJISAWA, Dirce Shizuko. Atividade Lúdica na Fisioterapia em Pediatria: Revisão de Literatura. Rev. bras. educ. espec. vol.23 nº.4, 2017.

VIANA, Flavia de Lima; FIGUEIREDO, Glória Lúcia Alves. Infecção pelo vírus Zika e a microcefalia: impacto no cotidiano das famílias. Convibra. 2017. Disponível em: < http://www.convibra.com.br/upload/paper/2017/72/2017_72_14589.pdf >. Acesso em: 20/05/2019.

XAVIER, Juliana. A importância da estimulação precoce em crianças com sequelas neurológicas. 2019. Disponível em: <http://www.iff.fiocruz.br/index.php/8noticias/323-estimulacao-precoce>. Acesso em: 27/05/2019. 